\title{
Predictor: The First Home Pregnancy Test
}

\author{
Jesse Olszynko-Gryn
}

Predictor, the first home pregnancy test, made its debut in Britain and other European countries in 1971. Designed and patented in the late 1960s by Margaret Crane, a New York graphic designer, it was manufactured and marketed by Chefaro, a subsidiary of the Dutch pharmaceutical company Organon. Neatly packaged in a green and white cardboard box, the test kit consisted of a transparent Perspex container holding a test-tube and dropper and fitted with an angled mirror at the base (figure 1). Freeze-dried reagents (made from rabbit serum and sheep red blood cells) rested at the bottom of the tube, and a tightly folded insert explained (with captioned pictures) how Predictor worked in twelve "easy" steps. These involved mixing a small amount of urine with tap water in the tube and then allowing the mixture to sit undisturbed for two hours, before finally reading the result in the mirror. The formation of a "doughnut-like ring" at the bottom of the tube indicated pregnancy, a "positive" result; no ring meant no pregnancy ("negative"). ${ }^{1}$

As do today's more streamlined products, Predictor functioned by detecting the presence or absence of the placental hormone hCG (human chorionic gonadotropin). This highly specific test can be traced back to the late 1920s, when pregnancy testing involved injecting immature female mice with urine and then killing and dissecting them to inspect their ovaries for visible changes induced by hCG. Mice were reliable enough, but using them was also expensive, laborious, and slow. Using rabbits was quicker but even costlier. Both were supplanted after World War II by imported South African toads that laid eggs and so did not have to be killed in the course of a test. Crucially, doctors were the main clients, and "differential diagnosis" (to distinguish normal from pathological gestation) was the main aim. Publicity was minimal, and so-called curiosity cases were discouraged. ${ }^{2}$

Animal injections were made obsolete when Organon launched Pregnosticon, a cheap, mass-produced test kit, in 1962 - the year after the birth control pill arrived in Britain. Pregnosticon opened the market to more entrepreneurial providers. It also contributed to a relaxation of moral standards and the erosion of medical authority. In 1965, commercial laboratories began serving women directly, not as "patients" but as "clients." The laboratories initially charged $£ 2$ for a test and (controversially) returned the result not to a doctor but to the woman herself. ${ }^{3}$

Abortion became legal in Britain in 1968, removing a major obstacle that (along with vivisection) had framed debates over pregnancy testing since the 1930s. In 1970, the

\footnotetext{
Jesse Olszynko-Gryn is a Chancellor's Fellow in the School of Humanities at the University of Strathclyde, Glasgow. His first book, A Woman's Right to Know: Pregnancy Testing in Twentieth-Century Britain, will reconstruct for the first time the remarkable transformation of pregnancy testing from an esoteric diagnostic technology to a commonplace of everyday life. He thanks Nadja Durbach for the opportunity to contribute to this series; Nick Hopwood for comments on an early draft; Lesley Hall, Meg Crane, and Polly Brownlee for assistance with primary sources; and Wellcome (106553/Z/14/Z) and AHRC (AH/T013281/1) for support. Please direct any correspondence to jesse.olszynko-gryn@strath.ac.uk.

${ }^{1}$ All above quotations are from the insert of a 1971 test kit. Courtesy of Meg Crane.

2 Jesse Olszynko-Gryn, "The Demand for Pregnancy Testing: The Aschheim-Zondek Reaction, Diagnostic Versatility, and Laboratory Services in 1930s Britain," Studies in History and Philosophy of Biological and Biomedical Sciences 47, Part B (2014): 233-47.

${ }^{3}$ Jesse Olszynko-Gryn, "Pregnancy Testing in Britain, c.1900-67: Laboratories, Animals and Demand from Doctors, Patients and Consumers" (PhD diss., University of Cambridge, 2014), 229.
} 
Pharmaceutical Society approved pregnancy testing (along with the open display of condoms). ${ }^{4}$ The British Medical Association objected to the test at every turn, on the grounds that women and pharmacists were not qualified to interpret the results, but society was changing; newspapers increasingly presented medical paternalism as anachronistic and pregnancy testing as achieving a "woman's right to know." An estimated 1.5 million pregnancy tests were performed nationally in 1971, the year that Predictor came on the market. ${ }^{6}$ According to survey data from around the same time, less than a third of women who used commercial services "would want to keep the child if they were pregnant.",7

Predictor was not predicated on any new technical innovation. Rather, it was a decadeold medical technology, Pregnosticon, redesigned for domestic use and thus full of disruptive potential. For this reason, Organon, a company that above all served the medical profession, took pains to reassure doctors that its consumer product would "not to disturb the normal DR/Patient relationship." Advertisements in the general press and the instructional insert likewise deferred to medical authority. Women, it was claimed, would test themselves and then go to their doctors for medical advice.

Predictor retailed for $£ 1.75$, undercutting most lab tests. For the pharmacist, this meant, after markup, a 57p profit on every pack sold, a handsome margin. But pharmacists, too, were reluctant to tread on doctors' toes. Boots, Britain's largest and historically conservative chain of pharmacies, refused to stock Predictor until the late 1970s. Some independent pharmacies objected also, on the grounds that women would make mistakes. The one in five pharmacies that did stock Predictor in 1971 sold a disappointing thirty thousand tests.

Nor did women universally embrace Predictor. The Women's National Commission, an umbrella body for women's organizations established by the government in 1969, urged a ban, citing (misplaced) concerns over the test's accuracy. And activists in the women's liberation movement rejected Predictor as a form of commodification. They organized, as a nonmedical, noncommercial alternative, free or at-cost clinics that combined pregnancy testing with sympathetic counseling, contraceptive advice, and referrals to providers of abortion or antenatal care. ${ }^{9}$ In 1974 (the year that family planning was incorporated into the National Health Service), the Consumers' Association stated that women were fully capable of correctly using Predictor but nevertheless sided with medical authority: "Ideally, your G[eneral] P[ractitioner] should be the person to find out for you whether or not you're pregnant." ${ }^{10}$ Many doctors, however, refused to test healthy married women (the "curiosity cases"), and many young unmarried women ("social cases") were reluctant to go to the family doctor.

\footnotetext{
${ }^{4}$ Stuart Anderson, "Community Pharmacy and Sexual Health in 20th Century Britain," Pharmaceutical Journal 266, no. 7129 (6 January 2001): 23-29; Ben Mechen, “'Closer Together': Durex Condoms and Contraceptive Consumerism in 1970s Britain," in Perceptions of Pregnancy from the Seventeenth to the Twentieth Century, ed. Jennifer Evans and Ciara Meehan (Basingstoke, 2016), 213-36.

${ }^{5}$ Olszynko-Gryn, "Pregnancy Testing in Britain," 240.

${ }^{6}$ Moira Keenan, "Do-It-Yourself Pregnancy Test," Times (London), 15 September 1971, 16.

7 "Survey of Women Using Pregnancy Test," Pharmaceutical Journal, 30 January 1971; 6, 13, 20, 27 February 1971; 6 and 13 March 1971.

${ }^{8}$ The National Archives, MH 156/633, Mr. A. B. Giles, undated report to the Lane Committee on the Working of the Abortion Act 1967.

${ }^{9}$ Jesse Olszynko-Gryn, “The Feminist Appropriation of Pregnancy Testing in 1970s Britain," Women's History Review 28, no. 6 (2019): 869-94.

${ }^{10}$ Consumers' Association, Sex with Health: The "Which?" Guide to Contraception, Abortion and Sex-Related Diseases (London, 1974), 54.
} 
The British Medical Association, for its part, responded to Predictor by petitioning the Department of Health and Social Security to reimburse general practitioners for pregnancy testing, including for "social" reasons. Footing the bill would be expensive, but it "would help to restore pregnancy testing to its rightful context — an essential part of general medical care." 11 The government, however, was reluctant to intervene. Predictor, as an apparatus, was exempt from the Medicines Act 1968, which covered drug efficacy and safety. Powers existed in the act "to extend its controls," but (Labour) ministers agreed in 1976 that the regulatory agency responsible for drugs was "overloaded and should take on no fresh commitments." 12 So, despite perennial complaints from paternalistic doctors that self-testing could harm women and even lead to deaths (by misdiagnosis or suicide), the Department of Health and Social Security decided against regulation. Predictor now had the state's assent.

Predictor was not commercially successful in Britain until 1976, when a massive marketing campaign significantly increased sales, especially in London and the Home Counties. Aligning the product more with cosmetics than with condoms or tampons, advertisements compared "getting a pregnancy test" to "buying a lip- stick." $13{ }^{13}$ Window stickers and display stands further promoted Predictor as "private, reliable, simple, early - the pregnancy test you do yourself." As a "British thing," Predictor was for a time synonymous with self-testing. It is the test that Pauline Mole uses in Sue Townsend's novel The Growing Pains of Adrian Mole. (Adrian, upon finding the "strange device," worries that his mother is "dab- bling in the occult." ${ }^{\prime \prime}$ ) And it contributed to a realignment of the power dynamics among women, doctors, and pharmacists. But after a decade as market leader, it was overtaken by Unilever's Clearblue, the first "midstream" self-test and a home- grown product of Britain's "biotech boom.",16

More than any other brand, Clearblue helped to construct a new kind of consumer: the career woman whose "biological clock" was ticking. The brand's ascent coincided with National Health Service cutbacks, the rise of health consumerism, and in vitro fertilization. Clearblue cemented self-testing as the new normal for a younger generation of women and pushed Predictor into second place. In 1996 pharmacies sold 500,000 Predictors - a 30 percent share of a national market worth around $£ 18$ million in retail sales. ${ }^{17}$

Today, pregnancy testing is technically free on the National Health Service, but most women will pay out of pocket for a home test (and most doctors will accept the result). Fertility and HIV self-tests, as well as morning-after pills and preconception vitamins, have joined pregnancy tests on pharmacy shelves. Predictor, mean- while, is a museum piece. A 1984 vintage kit, perhaps similar to the one used by Pauline Mole, is held by the Science Museum in London. When the Smithsonian acquired the prototype in 2015, it contributed to a growing appreciation of not only Margaret Crane's rightful place in the design history but also the neglected role of pregnancy testing in the permissive trend that liberalized access to family planning in the 1960s and 1970s. In contrast to histories of the birth control pill or abortion, however, the rise of home pregnancy testing in Britain is not primarily a tale of medicalization or law reform. Rather, it

\footnotetext{
11 “Pregnancy Testing,” British Medical Journal, no. 5785 (1971): 444-45.

12 The National Archives, MH 156/633, report by W. G. Robertson, 20 August 1976

13 The National Archives, MH 156/633, Girl about Town, 16 June 1976, n.p.

14 "Large Increase in Predictor Sales," Chemist and Druggist, no. 5058 (1977): 371.

${ }^{15}$ Sue Townsend, The Growing Pains of Adrian Mole (London, 1984), 23.

${ }^{16}$ Jesse Olszynko-Gryn, "Thin Blue Lines: Clearblue and the Drama of Pregnancy Testing in British Cinema and Television," British Journal for the History of Science 50, no. 3 (Sept. 2017): 495-520.

${ }^{17}$ Guy L'Aimable, “Supreme Survivor,” Chemist and Druggist, no. 6049 (1996): 256-57.
} 
should be seen as part of a process that diminished medical authority, transformed patients into consumers, and consolidated pharmacies as sites of reproductive choice.

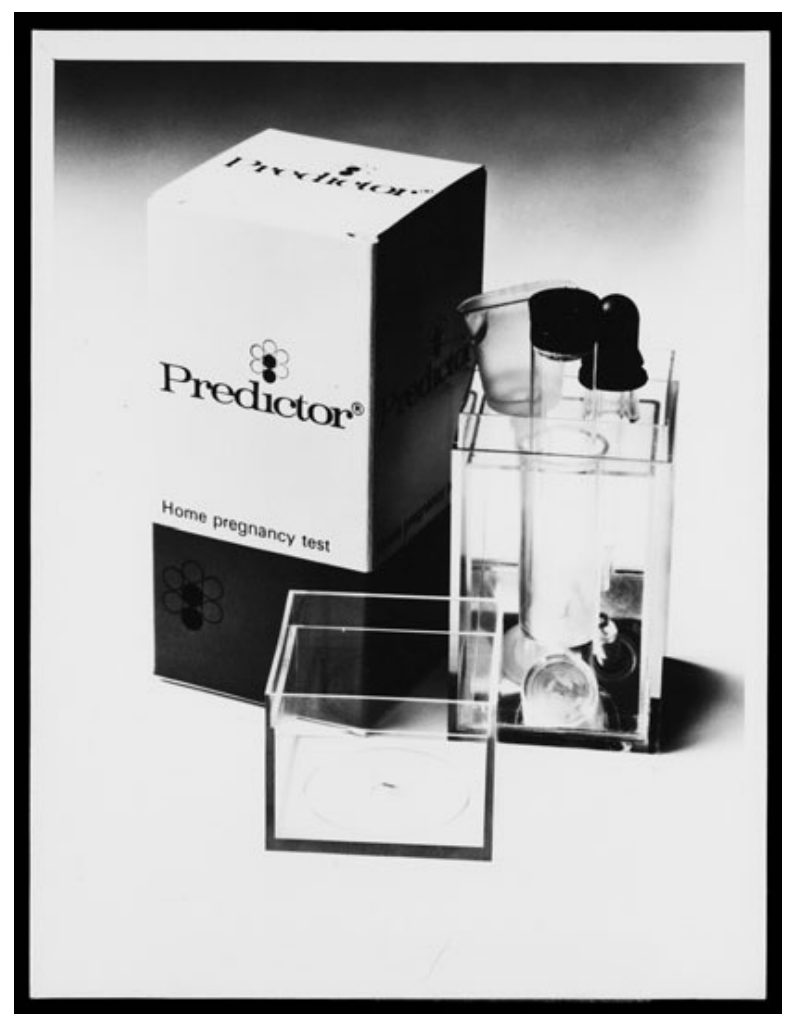

Figure 1-Publicity photograph of Predictor, 1971. PP/GRA/B.4: Box 1, Wellcome Library. 